\title{
companhia de navegação lloyd brasileiro: uma trajetória de déficit financeiro e desenvolvimento econômico*
}

\author{
Alcides Goularti Filho \\ Professor da Universidade do Extremo Sul Catarinense - UNESC, Doutor em Economia pelo \\ IE/Unicamp
}

\section{RESUMO}

O objetivo deste artigo é descrever e analisar a trajetória da Companhia de Navegação Lloyd Brasileiro, destacando a política de financiamento dos déficits, em paralelo ao avanço produtivo da companhia. $\mathrm{O}$ artigo está dividido em seis tópicos. Na Introdução, será apresentada uma breve descrição das condições materiais e políticas que levaram à criação do Lloyd Brasileiro, em 1890. Em seguida, abordaremos a fundação e o período da gestão privada sob a tutela do Estado, 18901913. O terceiro item envolve o período em que a companhia foi lentamente seguindo para uma centralização das ações, quando, finalmente SE transformou em patrimônio nacional, 1913-1937. O quarto discute o Lloyd Brasileiro como patrimônio nacional, no momento da industrialização pesada, 1937-1966. O quinto discute o período mais recente, quando a companhia foi reestruturada, transformada em sociedade anônima, até o início do processo de privatização, 1966-1989. E, por fim, os últimos momentos do Lloyd Brasileiro serão discutidos no sexto item, quando a companhia foi, aos poucos, sendo desmontada e privatizada. Nas considerações finais, apresentaremos um resumo dos motivos geradores dos déficits financeiros e da atuação do Lloyd Brasileiro.

Palavras-chave: navegação - história econômica - estatal - Lloyd Brasileiro

\section{Abstract}

This article aims to describe and analyze the trajectory of the Companhia de Navegação Lloyd Brasileiro detailing the policy of financing the deficits parallel to the advancement of manufacturing company. The article is divided into five topics. In the introduction will be a brief description of the material conditions and policies that led to the creation of the Lloyd Brasileiro in 1890. Then, we discuss about the foundation and the period of private management under the supervision of the State, from 1890 to 1913. The third item involves the period when the company was slowly according to a centralization of the shares when it finally turned into national heritage, 1913-1937. The fourth item discussed the Lloyd Brasileiro as national heritage at the time of heavy industrialization, 1937-1966. The fifth discusses the most recent period, when the company was restructured and transformed into a corporation, until the beginning of the process of privatization, 1966-1989. Finally, the last moments of Brazilian Lloyd will be discussed in the sixth item when the company was gradually being dismantled and privatized. In the final considerations, present a summary of the reasons resulting financial deficits and the role of Lloyd Brasileiro.

Keywords: navigation - economic history - state - Lloyd Brasileiro

* Pesquisa financiada pelo CNPq. Submetido: agosto, 2009; aceito: dezembro, 2009. E-mail: alcides@unesc.net 


\section{Introdução}

No último quartel do século XIX, a economia brasileira estava passando por momentos de significativas mudanças nas bases materiais, como a ampliação do trabalho assalariado, a formação dos complexos regionais agrário-mercantis exportadores, a expansão das ferrovias e a urbanização das principais cidades. Estas mudanças refletiam a ampliação do fluxo mercantil interno e externo, articulando, comercialmente, o mercado nacional. A navegação (marítima e fluvial) e as ferrovias substituíram os velhos caminhos desenhados pelos tropeiros e tornaram-se a espinha dorsal do sistema de transporte nacional. Dada a acumulação horizontal e extensiva do capital privado nacional, na navegação de cabotagem, em que as exigências de investimentos eram menores, havia a forte presença de companhias locais e regionais. Já na navegação de longo curso (exportação e importação), que exigia investimentos mais vultosos, havia somente a presença de companhias estrangeiras.

$\mathrm{Na}$ frota mercante nacional, destacavam-se duas grandes companhias: a Companhia Nacional de Navegação a Vapor, que fazia a Linha Sul (Rio de Janeiro-Rio Grande do Sul) e a Companhia Brasileira de Navegação a Vapor, que fazia a Linha Norte (Rio de Janeiro-Manaus). Porém, havia inúmeras companhias regionais que atendiam às demandas geradas pelos complexos exportadores, como a Companhia de Navegação Pernambucana, a Companhia de Navegação Baiana e a Companhia de Navegação do Maranhão (SILVA, 1902).

No front externo, a Guerra do Paraguai (1864-1870) revelou a precariedade da Marinha de Guerra Brasileira, que foi obrigada a solicitar suporte à navegação civil para atender às suas demandas bélicas. Para os oficiais da marinha, aparelhar a defesa naval era condição sine qua non para garantir a integridade do território. Como a Marinha Mercante era entendida como reserva da Marinha de Guerra, o aparelhamento da primeira significa a garantia de uma frota moderna, em caso de novos conflitos armados (MENDONÇA, 2001). Internamente, a franca expansão do complexo cafeeiro exigia um esforço maior das ferrovias, dos portos e da navegação, por meio do transporte da rubiácea em direção aos portos, e do transporte de imigrantes em direção às fazendas. Com não havia companhias nacionais no longo curso, este serviço era reali-

\section{6 | Alcides Goularti Filho}


zado exclusivamente por navios de bandeira estrangeira, tanto nas exportações como nas importações.

Diante deste cenário, o Vice-Almirante Barão de Jaceguay esboçou um projeto de uma companhia de navegação entre o Brasil e a Europa, publicado na Revista Marítima de 1886, denominada Lloyd Brasileiro. Reforçando a ideia de montar uma grande companhia de navegação como reserva da Marinha de Guerra, Jaceguay propôs que o Lloyd Brasileiro fosse constituído a partir da fusão de todas as companhias nacionais de navegação, com sede no Rio de Janeiro. Todas as linhas seriam mantidas, criando-se, apenas, duas linhas transoceânicas: "uma para os portos do Ocidente e Norte da Europa e outra para alguns portos do Mediterrâneo" (JACEGUAY, 1888:15).

Como resultado da proposta elaborada pelo Barão de Jaceguay, foi incluída na Lei n. 3.397, de 24 de novembro de 1888, que fixava as despesas gerais do Império para o exercício de 1889, a autorização para o Ministério da Agricultura, Comércio e Obras Públicas contratar o Barão para organizar uma companhia de navegação a vapor, que realizasse viagens entre o Brasil e a Europa, com uma subvenção de 25:000\$000 por viagem redonda, até a soma de 300:000\$000 por 12 viagens. Em seguida, o Decreto n. 10.106, de 10 de novembro de 1888, concedeu ao Barão, ou à empresa que ele organizasse, os favores para custear duas linhas de paquetes entre o porto de Santos e os de Hamburgo e Genova. Além das linhas regulares, estava garantido que a companhia organizada poderia transportar, anualmente, até 20.000 imigrantes europeus por um prazo de cinco anos. Portanto, a criação desta nova companhia transoceânica estava associada à expansão do complexo cafeeiro que demandava mão de obra imigrante. Em seguida, Jaceguay organizou a Companhia Transatlântica de Navegação, que, na realidade, nunca entrou em operação.

\section{Gestão privada sob a tutela do Estado - 1890-1913}

Inicialmente, a política de estímulo aos transportes da jovem República, proclamada em 1889, foi a mesma do velho Império, ou seja, a prioridade eram as ferrovias, com as garantias de juros e, num segundo plano, vinha a navegação fluvial e marítima, com as subvenções. No 
setor da navegação, o país havia herdado uma Marinha Mercante sucateada, inclusive com a presença do capital externo na cabotagem.

Com o objetivo de efetivamente criar uma companhia de navegação transoceânica, o Barão de Jaceguay reuniu-se com os capitalistas Antonio Paulo de Mello Barreto e Manuel José da Fonseca, e, amparados pelos diretores da Companhia Nacional de Navegação, encaminharam ao Ministério da Agricultura um pedido de autorização para organizar o Lloyd Brasileiro. Como resposta, foi aprovado o Decreto n. 208, de 19 de fevereiro de 1890, que autorizou a organização do Lloyd Brasileiro, cujo preâmbulo reforçava a ideia de a Marinha Mercante atuar como reserva de guerra: "A organização proposta tem o sufrágio e o exemplo de outras nações adiantadas, pelos seus efeitos práticos e pelas vantagens múltiplas que traz ao Estado na defesa marítima e como auxiliar da Armada Nacional, em caso de guerra" (Decreto n. 208/1890).

Após a publicação do decreto, foram iniciadas as tratativas para a formação da nova empresa, que se baseou no processo de fusão entre a Companhia Transatlântica de Navegação (que estava apenas no papel), a Companhia Progresso Marítimo (cujo patrimônio estava hipotecado ao Banco do Brasil), a Companhia Espírito Santo e Caravelas (que havia contraído dívidas junto a bancos londrinos), a Companhia Nacional de Navegação a Vapor e a Companhia Brasileira de Navegação a Vapor.

Em seguida à fusão, os diretores do Lloyd Brasileiro obtiveram junto ao Banco do Brasil um empréstimo de 12.000:000\$000, utilizados para adquirir a Ilha Mocanguê e uma oficina de máquinas (LOBO, 1922). O Decreto n. 857, de 13 de outubro de 1890, que regulou os serviços da nova companhia, obrigou o Lloyd Brasileiro a realizar as seguintes viagens: $1^{\text {a }}$-Linhas transatlânticas entre o porto de Santos e Hamburgo e entre o porto de Santos e Gênova; $2^{\mathrm{a}}$ - Linha do norte: entre os portos do Rio de Janeiro e o norte da República; $3^{a}$-Linha do sul: entre Rio de Janeiro, Porto Alegre e Montevidéu; $4^{a}$ - Linha intermediária: entre os portos da capital da República de Montevidéu; $5^{a}$ - Linha fluvial de Santa Catarina: entre os portos de Tijucas, Porto Belo, Itajaí, São Francisco do Sul e Laguna; $6^{a}$ - Linha fluvial de Mato Grosso: entre Montevidéu e Cuiabá; $7^{\mathrm{a}}$ - Linha do Espírito Santo e Canavieiras: entre os portos da capital capixaba e os de São Mateus e Canavieiras.

\section{8 | Alcides Goularti Filho}


Além da autorização para a criação do Lloyd Brasileiro, a maior mudança advinda com a República, no setor da navegação de cabotagem, foi a garantia do monopólio para as companhias nacionais, prevista no parágrafo único do artigo 13 da Constituição de 1891. Esta era a posição de alguns republicanos positivistas, que defendiam o fortalecimento do capital nacional e a formação de um sistema nacional de economia.

Mesmo começando com uma frota de 65 navios, somando 48.289 TPB e uma subvenção anual de 1.487:454\$600, o que representava 55,42\% do total das subvenções despendidas pelo Estado, o início do Lloyd Brasileiro não foi dos melhores. No ano seguinte à sua fundação, os problemas financeiros e administrativos começaram a surgir, levando à sua primeira insolvência. Como tentativa de evitar a quebra da nascente companhia, no ano seguinte, ela foi incorporada à Empresa de Obras Públicas do Brasil, que dispensou as linhas transatlânticas. Após essa incorporação, até o ano de 1913, quando foi encampado e declarado patrimônio nacional, o Lloyd Brasileiro teve oito regimes administrativos diferentes: passou por intervenções do governo federal e do Banco do Brasil, foi transformado em sociedade anônima, sofreu uma liquidação forçada e seus bens foram vendidos em leilão. Novamente foi reorganizado nos moldes de uma empresa privada, até ser definitivamente encampado em 1913. No entanto, no meio desta turbulência administrativa, o Lloyd Brasileiro nunca parou seus serviços no transporte de pessoas e mercadorias, servindo a todo o litoral brasileiro e às principais bacias hidrográficas.

Ao lado do Lloyd Brasileiro, também se destacavam a Companhia Pernambucana, a Companhia Bahiana e a Companhia do Maranhão, que igualmente eram subvencionadas. Nos anos seguintes, surgiram mais duas grandes companhias que ampliaram a frota mercante nacional: a Companhia Nacional de Navegação Costeira, fundada em 1891, e a Companhia Comércio e Navegação (CCN), fundada em 1905 (BRASIL, 1910).

Nosso objetivo, neste artigo, não é detalhar as mudanças em cada regime do Lloyd Brasileiro, mas, sim, analisar as tendências, enfocando as crises e o desenvolvimento. Segue, abaixo, um quadro que resume todas as mudanças administrativas e patrimoniais ocorridas entre 1890 e 2002. 
Quadro 1: Regimes administrativos e patrimoniais do Lloyd Brasileiro de 1890 a 2002

\begin{tabular}{|c|c|}
\hline REGIME & DATA \\
\hline 1. Lloyd Brasileiro & $19 / 02 / 1890$ a $02 / 10 / 1891$ \\
\hline $\begin{array}{l}\text { 2. Lloyd Brasileiro seção de navegação Empresa de Obras } \\
\text { Públicas do Brasil }\end{array}$ & 03/10/1891 a 09/12/1892 \\
\hline 3. Sociedade Anônima Lloyd Brasileiro & $10 / 12 / 1892$ a $28 / 09 / 1894$ \\
\hline $\begin{array}{l}\text { 4. Sociedade Anônima Lloyd Brasileiro sob a intervenção do } \\
\text { governo federal }\end{array}$ & $29 / 09 / 1894$ a $11 / 03 / 1895$ \\
\hline $\begin{array}{l}\text { 5. Sociedade Anônima Lloyd Brasileiro sob a fiscalização do } \\
\text { Banco do Brasil }\end{array}$ & $11 / 03 / 1895$ a $15 / 03 / 1899$ \\
\hline 6. Sociedade Anônima Lloyd Brasileiro em liquidação & 16/03/1899 a $31 / 07 / 1901$ \\
\hline $\begin{array}{l}\text { 7. Sociedade Anônima Lloyd Brasileiro sob a administração } \\
\text { do Banco do Brasil }\end{array}$ & 01/08/1901 a $07 / 01 / 1903$ \\
\hline 8. Companhia Novo Lloyd Brasileiro & 07/01/1903 a 30/06/1906 \\
\hline 9. Lloyd Brasileiro Sociedade em Comandita por Ações & $30 / 06 / 1906$ a $21 / 12 / 1909$ \\
\hline 10. Lloyd Brasileiro Sociedade Anônima & $24 / 12 / 1909$ a $12 / 08 / 1913$ \\
\hline 11. Lloyd Brasileiro Patrimônio Nacional & $13 / 08 / 1913$ a $28 / 12 / 1920$ \\
\hline 12. Companhia de Navegação Lloyd Brasileiro & $28 / 12 / 1920$ a $11 / 06 / 1937$ \\
\hline 13. Lloyd Brasileiro Patrimônio Nacional & $11 / 06 / 1937$ a $31 / 12 / 1966$ \\
\hline 14. Companhia de Navegação Lloyd Brasileiro & 01/01/1967 a 15/01/1989 \\
\hline 15. Companhia de Navegação Lloyd Brasileiro em extinção & 15/01/1989 a $11 / 12 / 2002$ \\
\hline
\end{tabular}

Fonte: Relatórios do Lloyd Brasileiro.

Do ponto de vista financeiro, este período de 23 anos, entre 1890 e 1913, também foi um dos mais críticos e instáveis. Na verdade, o Lloyd Brasileiro já teve um início truncado, com a incorporação da Companhia Progresso Marítimo e da Companhia Espírito Santo e Caravelas, ambas insolventes e com equipamentos obsoletos. Esta última administrava a Estrada de Ferro Itapemirim, que estava mergulhada em dívidas com casas bancárias londrinas. Em seguida, vieram novas incorporações mal realizadas, como compra de navios da Companhia Bahiana de Navegação, da Companhia Grão-Pará e da Buarque Line \& Cia. Ltda. (BRASIL, 1899; BURLAMAQUI, 1918).

Para saldar dívidas acumuladas pela compra de navios usados e pela fusão de companhias endividadas, foram realizados empréstimos junto ao Banco do Brasil e a bancos londrinos. Dos cinco empréstimos realizados no período de 1890 a 1910, dois foram efetuados com o objetivo de saldar débitos contraídos em função das incorporações, como é o caso do empréstimo de $£ 200.000$, feito para saldar os débitos da Estrada de Ferro Itapemirim, e o de Rs 14.000:000\$000, que saldaria dívi- 
das acumuladas em apenas dois anos de existência do Lloyd Brasileiro. Os dois últimos empréstimos foram realizados para comprar novos navios encomendados na Europa (LOBO, 1922). Porém, estes empréstimos foram pagos somente após a intervenção estatal em 1913, quando o Tesouro passou a fazer constantes aportes financeiros para evitar, novamente, a insolvência da companhia. (LLOYD BRASILEIRO, 1929).

Durante o período de gestão privada, tutelada até 1913, havia constantes reclamações dos diretores do Lloyd Brasileiro de que seus navios eram obrigados a fazer linhas deficitárias em função das determinações do Ministério da Indústria,Viação e Obras Públicas. Os exemplos mais citados são os da linha fluvial até o Mato Grosso, da navegação lacustre no Rio Grande do Sul, da linha entre Recife e Fernando de Noronha e da destinada ao porto de Laguna. E, para agravar ainda mais a situação, os preços cobrados pelo transporte das mercadorias e das passagens estavam bem abaixo do praticado por outras companhias (BRASIL, 1910). Estava posto o impasse. Por um lado, o Lloyd Brasileiro privado tinha o objetivo de lucro; por outro, o Ministério visava atender às regiões que não eram servidas por outras companhias de navegação.

Outro fator que agravou a situação da companhia foi os gastos com a manutenção das embarcações. Como a frota era muito obsoleta, sobretudo a incorporada da Nacional e a da Brasileira, constantemente seus navios ficavam atracados nas oficinas para fazer os devidos reparos. Esta situação, segundo as análises dos diretores da companhia, era o real motivo que impedia o Lloyd Brasileiro de dar resultados financeiros positivos. Nos relatórios da companhia, este ponto era sempre destacado pelos diretores, que insistiam na comparação com outras companhias mais eficientes, como era o caso da Companhia Nacional de Navegação Costeira e da Companhia Comércio e Navegação (BRASIL, 1892; BRASIL, 1912; LLOYD BRASILEIRO, 1917).

Para tentar amenizar o problema da obsolescência da frota, durante a segunda gestão de Manuel Buarque de Macedo, de 1906 a 1911, mediante os empréstimos realizados junto a N. M. Rothschild \& Comp., foram adquiridos 13 novos navios construídos em estaleiros ingleses. Também foram criadas a Linha Americana e a Linha do Rio da Prata, em 1908, e a Linha Européia, em 1910, ou seja, somente 18 anos após a fundação do Lloyd Brasileiro, foi alcançado seu objetivo inicial, que era dotar o país de uma companhia transoceânica (LLOYD BRASILEIRO, 1917). 
Há que se destacar que, mesmo com toda a turbulência administrativa e as profundas dificuldades financeiras entre 1890 e 1913, os serviços do Lloyd Brasileiro nunca foram paralisados, inclusive durante a liquidação forçada, entre março de 1899 e julho de 1901. No Anexo 1, podemos acompanhar esta primeira fase. Do ponto de vista da estrutura material, a trajetória do Lloyd Brasileiro divide-se em dois momentos: de 1890 a 1906 e de 1906 a 1913. O ponto de inflexão está na segunda gestão de Manuel Buarque de Macedo, que renova a frota e cria três linhas internacionais. Com isso, o volume de carga transportada passa de 105.009 toneladas, em 1905, para 141.703 e 381.237, nos dois anos seguintes. O mesmo ocorreu com a TPB, que passou de 30.363 para 62.665 e 69.296, respectivamente, de toneladas transportadas.

Com relação à frota, houve a retirada de navios obsoletos e a entrada em operação de novas embarcações vindas da Inglaterra, passando de 45 navios, em 1906, para 64, em 1912. Durante a gestão de Manuel Buarque de Macedo, ocorreu um crescimento nominal da receita do vapores, de 1907 a 1912, de 31,68\%,e as subvenções, que representavam 12,01\% dessa receita, em 1907, passaram para 9,12\%, em 1912.

Apesar dos avanços produtivos e financeiros, o volume da dívida do Lloyd Brasileiro aumentava paulatinamente. Apenas a dívida com o Banco do Brasil, em 1913,era de Rs 31.485:484\$060, correspondia a 1,8 vezes da receita dos vapores, excluindo a dívida de $\mathcal{E} 4.100 .000 \mathrm{com}$ bancos estrangeiros. Diante desta insolvência e das recomendações da assembléia geral dos acionistas, o Decreto n. 10.387, de 13 de agosto de 1913, autorizou o Ministério da Fazenda a emitir apólices no valor de Rs 32.000:000\$000 para saldar as dívidas da Companhia junto ao Banco do Brasil, e, ao mesmo tempo, incorporou seus ativos ao patrimônio nacional, que estava avaliado em Rs 43.913:630\$000 (LLOYD BRASILEIRO, 1919).

\section{Centralização estatal na navegação - 1913-1937}

Logo após a incorporação do Lloyd Brasileiro ao patrimônio nacional, sob a responsabilidade do Ministério da Fazenda, foram feitas duas tentativas, em vão, de arrendá-lo ao capital privado. As dificuldades da companhia eram amplamente conhecidas pelos capitalistas brasileiros, 
portanto, não valia a pena investir num empreendimento sem expectativas de rendimentos futuros. Independente das tentativas fracassadas, as obrigações financeiras da companhia continuavam vencendo, e passaram a ser saldadas pelo Banco do Brasil e pelo Tesouro Nacional (BRASIL, 1915).

A Primeira Guerra Mundial (1914-1918) permitiu ao Lloyd Brasileiro dar um salto produtivo e equilibrar suas finanças. A guerra e o recrutamento dos navios da Marinha Mercante das nações beligerantes abriram um flanco para o Lloyd Brasileiro ampliar suas linhas transoceânicas. Com a declaração de guerra à Alemanha, todos os 43 navios germânicos, que estavam atracados nos portos brasileiros, foram arrastados e incorporados à frota nacional. Dentro da reserva naval, o Lloyd Brasileiro assumiu o comando do processo de ordenamento da Marinha Mercante brasileira, incorporando 18 navios da Companhia Comércio e Navegação e 18 da Companhia Nacional de Navegação Costeira. Nesta ocasião, foi evocado, pela primeira vez, um dos objetivos da sua fundação: servir como reserva da Marinha de Guerra. Esta situação atípica para o Lloyd Brasileiro possibilitou gerar superávit no seu balanço contábil em 1915, que durou por mais quatro anos (BRASIL, 1917; BRASIL, 1922; GAMA, 1982).

Com o armistício e a volta da normalidade no comércio mundial, a situação favorável do Lloyd Brasileiro começou a se reverter. A carga transportada pela companhia, que passou de 451.315 toneladas, em 1914, para 949.631, em 1918, caiu para 490.230, em 1920 (Anexo 1). Além disso, a ampliação da frota com os navios ex-alemães trouxe consigo um aumento considerável dos custos de manutenção. Somava-se a isso a obsoleta frota, a manutenção das várias linhas deficitárias e os baixos preços dos fretes e das passagens.

Em 1920, novamente o Lloyd Brasileiro viu-se numa situação de insolvência, acumulando déficits e mais uma solução paliativa foi proposta para a companhia. O Decreto n. 14.577, de 28 de dezembro de 1920, reorganizou o Lloyd Brasileiro, constituindo-o em sociedade anônima,formada com capital de 30.000:000\$000, sendo que a União subscreveu com 99,6\% das ações, uma reorganização amparada pelo Estado, que, mais uma vez, assumiu todos os ônus da "nova" companhia.

Nos anos 1920, a economia brasileira passou por uma diversificação produtiva com o surgimento de setores industriais mais complexos e 
dinâmicos, como cimento, ferro, aço, metal-mecânico, papel e celulose, produtos de borracha, químicos e frigoríficos, o que significava mais importações (SUZIGAN, 2000). Ao mesmo tempo, houve novos surtos na produção de café e a decadência na produção de borracha. Este movimento rebatia nos portos e na navegação, via exportações ou importações, que exigia maior atuação das companhias náuticas, para atender às demandas nacionais que estavam num rápido processo de integração comercial.

Mais do que um período de diversificação da base industrial, os anos 1920 representaram para o Brasil um período de transição de uma economia baseada num padrão de acumulação agrário/mercantil exportador, cujo maior indutor da renda era o complexo cafeeiro, para um novo padrão de acumulação, baseado no capital industrial. Os anos 1920 engendraram as condições necessárias para a ruptura promovida pela Revolução de 1930 (AURELIANO, 1981).

A crise mundial dos anos de 1930, o arrefecimento do comércio mundial e a quebra do padrão-ouro causaram mudanças substanciais nas economias periféricas, que passaram a proteger seus sistemas produtivos, alargando o mercado interno. Neste contexto, dentro do projeto de nação comandado porVargas, o Lloyd Brasileiro tornou-se um elemento determinante na integração da economia nacional. As vicissitudes financeiras foram facilmente solucionadas, com créditos aprovados junto ao Ministério da Fazenda. Mesmo com autonomia financeira, crédito e isenções, os problemas econômicos da companhia eram resolvidos temporariamente, porém eram repostos num nível de complexidade maior. No bojo da crescente centralização das funções do Estado, a Lei n. 420, de 10 de abril de 1937, autorizou o governo federal a anular todas as dívidas e os créditos junto ao Tesouro Nacional e ao Banco do Brasil. Mais uma vez, o Lloyd Brasileiro foi salvo pela ação direta do Estado, que, em seguida, por meio do Decreto $\mathrm{n}$. 1.708, de 11 de junho de 1937, reorganizou-se, incorporando-se, novamente, ao patrimônio nacional. 


\section{Lloyd Brasileiro, Patrimônio Nacional - 1937-1966}

Durante o Estado Novo (1937-1945), o projeto nacional de industrialização de Vargas ganhou contornos mais claros, cristalizando-se na construção do complexo siderúrgico brasileiro. No sistema de transportes, quase todas as ferrovias foram encampadas, as rodovias passaram a ter prioridade na agenda do Ministério da Viação e Obras Públicas, e, na navegação, o Lloyd Brasileiro iniciou uma nova etapa, mais uma vez sob a condição de Patrimônio Nacional.

Com suas dívidas saldadas pela União, o Lloyd Brasileiro começa o ano de 1937 com uma subvenção anual de Rs 40.000:000\$000, e a garantia de que a compra de novas embarcações seriam todas avalizadas pelo Banco do Brasil ou pelo Ministério da Fazenda, ou seja, estavam dadas as condições para a companhia ter um bom desempenho econômico.

Ledo engano, pois a sua frota continuava obsoleta e nenhuma das linhas, que eram deficitárias nas décadas anteriores, foi desativada. Havia, basicamente, dois motivos que impediam a companhia de desativar estas linhas deficitárias: o compromisso que tinha em atender às demandas regionais, integrando-as ao mercado nacional, e a pressão dos parlamentares que exigiam que o Lloyd Brasileiro cumprisse suas funções de empresa estatal, sem o objetivo do lucro, atendendo às comunidades, por mais distantes que fossem. Esta política do Lloyd Brasileiro, adotada desde sua fundação, pode ser observada no relatório de 1943 da companhia, durante a gestão do Comandante Mario da Silva Celestino:

Nossa finalidade como empresa de navegação oficial não era a da obtenção material do lucro, como qualquer congênere particular, mas o superior encargo de servir à defesa nacional, de abastecer as nossas populações e dar escoamento à produção, onde quer e como o exigem os superiores interesses do país (LLOYD BRASILEIRO, 1943:XXVII).

Novamente, foi outro evento externo que gerou resultados produtivos e financeiros para o Lloyd Brasileiro: a Segunda Guerra Mundial de 1939 a 1945. Nos três primeiros anos da guerra, o Lloyd Brasileiro ampliou suas viagens transoceânicas, elevando o volume transportado de 1.125.000 toneladas, em 1939, para 2.300.000, em 1941, normalizando em seguida. 
Foi, neste momento, que a companhia passou a ser de responsabilidade da recém-criada Comissão da Marinha Mercante (CMM).

Com o fim da guerra, novamente o fantasma da insolvência financeira voltou a rondar os escritórios do Lloyd Brasileiro. Após seis anos de superávits, o ano de 1949 marca o início de mais uma etapa de constantes déficits, que se irão reverter somente em 1964. Com relação ao volume de carga transportada, podemos observar uma longa e lenta queda, passando de 2.100 .000 toneladas, em 1945, para 1.216.930, em 1966.

Dois fatores explicam esta queda, a presença da Navegação Costeira (encampada em 1942, no transporte de cabotagem), a guerra dos fretes no comércio mundial entre os grandes oligopólios do setor da navegação e o aumento exponencial do transporte rodoviário de longa distância. Este último era reforçado pelos planos rodoviários e pelos maciços investimentos feitos na construção e na expansão da malha rodoviária.

No início dos anos de 1950, a frota mercante nacional estava passando por sérias dificuldades, chegando a ponto de não conseguir atender ao mercado nacional. A prioridade do governo era promover a expansão do transporte de longo curso, uma vez que as rodovias estavam integrando o mercado nacional, acelerando o processo de distribuição e circulação das mercadorias. Em 1951, a frota de longo curso era composta por 20 navios e representava, apenas, $4 \%$ do volume das exportações brasileiras, representando uma evasão de divisas no Balanço de Pagamento na conta "fretes e seguros" (BRASIL, 1952).

Como um país com uma linha costeira de quase nove mil quilômetros tinha um comércio de cabotagem tão pequeno e precário? Para o processo de acumulação capitalista, a distribuição e a circulação das mercadorias estavam sendo feitas pelas rodovias, portanto, as deficiências na Marinha Mercante não eram um entrave para o crescimento econômico.

Contando com a navegação interior, havia no país 119 armadores privados, "a maior parte deles empresas de pouca expressão" (COMISSÃO DA MARINHA MERCANTE, 1957:6). No transporte de longo curso, atuavam apenas o Lloyd Brasileiro (com 24 navios), a Frota Nacional de Petróleo (FRONAPE - criada em 1949 e incorporada pela Petrobrás em 1952, com 25 navios) e a Companhia Siderúrgica Na- 
cional (CSN, com 2 navios), que eram responsáveis por apenas 3,9\% das exportações e 10,5\% das importações. A cabotagem de longa distância era quase um serviço exclusivo do Estado. Além do Lloyd Brasileiro e da Navegação Costeira, a FRONAPE, e a CSN, também atuavam no transporte de matéria-prima. Em toneladas por milhas transportadas, 50\% eram da responsabilidade de empresas estatais (COMISSÃO DA MARINHA MERCANTE, 1957).

No início dos anos de 1950, era nítido que a estrutura do setor de navegação não atendia à demanda do mercado interno, que estava em franca expansão, dado o acelerado processo de industrialização, urbanização e integração do mercado nacional. O Estado brasileiro, que estava assumindo formas superiores de organização capitalista, atendendo às exigências do processo de acumulação, precisava dar uma resposta consistente ao setor de navegação. Num estudo sobre o "Reaparelhamento da Marinha Mercante", elaborado pelo Conselho de Desenvolvimento, ligado à Presidência da República, em 1956, no início do Plano de Metas, após fazer um amplo e sombrio diagnóstico da Marinha Mercante e da construção naval, foram propostas duas medidas: a estatização ou a liberalização. A primeira não era recomendada, pois as companhias estatais de navegação representavam pesado ônus para o orçamento federal. A segunda era liquidar as companhias estatais, o que prejudicaria a cabotagem de longa distância, uma vez que não havia capital privado nacional capaz de assumir os serviços da Lloyd e da Navegação Costeira.A proposta foi a seguinte:"O sistema atual deve ser mantido, com a progressiva entrega dos serviços aos particulares, desde que sejam criadas condições para que a iniciativa privada possa desenvolver-se em bases sólidas, dentro do regime de serviço público (CONSELHO DE DESENVOLVIMENTO, 1956:7).

As dificuldades para renovar a frota oficial e fazer novas aquisições para os armadores privados deveriam ser resolvidas, desenvolvendo a indústria da construção naval, estimulando as empresas nacionais, atraindo multinacionais e criando uma linha de financiamento para renovar a frota. Tais propostas deveriam ser feitas mediante a criação de uma taxa de reaparelhamento da Marinha Mercante, que formaria um fundo específico para financiá-la (CONSELHO DE DESENVOLVIMENTO, 1956). 
Dentro do Plano de Metas, a Marinha Mercante (Meta 11) e a construção naval (Meta 28) eram complementares, uma vez que não era mais possível pensar na renovação da frota oficial sem o desenvolvimento de uma indústria naval nacional, forte e integrada. Com a criação da Taxa de Renovação da Marinha Mercante (TRMM) e do Fundo da Marinha Mercante (FMM), em 1958, o setor foi dotado de um poderoso mecanismo de financiamento, que possibilitou a execução das metas propostas no Plano.

A partir desse momento, a CMM deixava de ser apenas um órgão de registro e controle da navegação nacional, para se tornar um instrumento de política de incentivos para o setor de navegação e a grande indústria da construção naval, gerando expectativas positivas no setor. Com já havia a indústria de aço no país, a implantação e a expansão da indústria da construção naval seria altamente beneficiada. Estes eram os resultados dos desdobramentos da industrialização pesada, que gestava os ciclos endógenos de acumulação.

O limite produtivo do Lloyd Brasileiro era amplamente conhecido, e o acúmulo de déficit já não assustava mais o executivo. Mesmo assim, seria impossível parar uma frota de 64 navios, que representava $31,63 \%$ da TPB nacional, e transportava 1.900 .000 toneladas, sendo que, na cabotagem, atendia a todas as regiões brasileiras e, no longo curso, mantinha as Linhas Americanas (Nova York e Novas Orleans), Européias (Norte e Mediterrâneo) e do Rio da Prata (LLOYD BRASILEIRO, 1957).

A nova política para a Marinha Mercante, no bojo do Plano de Metas, não era a de extinguir o Lloyd Brasileiro e a Navegação Costeira, mas estimular a expansão de companhias privadas nacionais. Também ficou decido que a Navegação Costeira ficaria apenas com a cabotagem marítima, e o Lloyd Brasileiro com a de longo curso. Esta divisão foi posta em prática somente a partir de meados dos anos de 1960, e marcou definitivamente os rumos do Lloyd Brasileiro nas décadas seguintes (LLOYD BRASILEIRO, 1963),

Há que se destacar que as sete primeiras entregas feitas para o setor de navegação nacional, pela recém-instalada indústria da construção pesada, foram destinadas ao governo; sendo seis para o Lloyd Brasileiro (BRASIL, 1964). Isso demonstra o papel determinante que teve o Lloyd Brasileiro no arranco inicial da indústria da construção naval. 
Com o golpe militar, em abril de 1964, ocorreu uma profunda mudança nas orientações das políticas da CMM e na condução dos negócios do Lloyd Brasileiro e da Navegação Costeira. Com o intuito de "remover as heranças dos governos anteriores", Fernando Frota e José Celso de Macedo Soares Guimarães, à frente da CMM, ambos com forte orientação privatista, mudaram os rumos das duas companhias de navegação brasileira (FROTA, 1965; GUIMARÃES, 1997). Para enfrentar as constantes greves, optaram pelo controle dos sindicatos e deram iniciou a uma ampla política de demissões.

O Lloyd Brasileiro voltou a afretar navios mais equipados para atender às demandas mais qualificadas. Com isso, enfrentava a concorrência externa, que o excluía do mercado internacional. Também foram extintas as subvenções para todas as companhias de navegação (LLOYD BRASILEIRO, 1966). Porém, a maior mudança ocorreu com a publicação do Decreto-Lei n. 67, de 21 de novembro de 1966, que extinguiu o Lloyd Brasileiro, Patrimônio Nacional, e a Companhia Nacional de Navegação Costeira,Autarquia Federal, e autorizou a constituí-las como sociedades anônimas.

\section{Recuperação temporária e agonia final - 1967-1989}

A alteração do nome da CMM para Superintendência Nacional da Marinha Mercante (SUNAMAM) não significou apenas uma simples mudança de nomenclatura, mas a centralização e o fortalecimento das políticas voltadas para a Marinha Mercante e a construção naval. A SUNAMAM passou a ter amplos poderes sobre a navegação marítima e fluvial, envolvendo os fretes, as empresas de navegação, a elaboração de planos para a construção naval e a liberação de recursos. Este poder atribuído à SUNAMAM estava garantido pelos vultosos recursos que ela gerenciava junto ao FMM. O fortalecimento da SUNAMAM inaugurou uma nova fase para o setor, pautada na proteção à navegação nacional, no apoio aos armadores nacionais e no estímulo à indústria da construção naval pesada. Concretamente, estava consolidada a indissociabilidade entre Marinha Mercante e construção naval, com claros objetivos de expandir e fortalecer a economia nacional. 
No tocante ao estímulo às companhias nacionais, a reestruturação do Lloyd Brasileiro, transformando-o em sociedade anônima, e a dissolução da Navegação Costeira em 1966 (que passou a se dedicar apenas aos reparos navais), abriu espaço para as companhias privadas de navegação. Na época, a intenção da CMM já era formar grandes companhias, ao invés de pulverizar o setor em pequenas e médias empresas. No início dos anos de 1960, já havia seis companhias privadas que atuavam no longo curso, totalizando apenas oito navios com 35.810 toneladas (COMISSÃO DA MARINHA MERCANTE, 1961).

Fortalecido pela mudança estatutária, ocorrida no início de 1967, o Lloyd Brasileiro, após novos aportes do Tesouro para saldar débitos, partiu para profundas mudanças produtivas, retirando de circulação navios muitos obsoletos, desativando o transporte de passageiros, transferindo a cabotagem para as companhias nacionais, afretando navios e renovando a frota. Estas mudanças, associadas à retomada do crescimento da economia brasileira no final dos anos de 1960, inauguraram um novo ciclo expansivo de expectativas favoráveis para o Lloyd Brasileiro, com bons resultados financeiros e produtivos.

A partir de 1964, o Lloyd Brasileiro foi alvo de constantes críticas dos liberais, que acusavam que a sua estrutura era "inchada", devido ao número excessivo de trabalhadores. Desde a sua fundação, a cada fusão e compra de navio usado, de companhias nacionais, o Lloyd Brasileiro assumia também o quadro de funcionários. Os anos 1930 e 1940 foram o período em que mais cresceu o quadro, chegando a 12.780 trabalhadores em 1948 (Anexo 1).

Esta situação começou reverter-se, lentamente, nos anos seguintes, chegando a 8.150 trabalhadores em 1963 (LLOYD BRASILEIRO, 1960-1963). Porém, o corte maior veio, sobretudo, após 1966, quando a empresa foi reestruturada e o "excesso" de pessoal foi redistribuído para outros órgãos governamentais, por meio da publicação de inúmeros decretos entre 1967 e 1973. Em 1970, eram apenas 2.800 trabalhadores, quadro que se manteve estável nas décadas seguintes. Para os diretores da CMM, este era um grande problema econômico e político para o Lloyd Brasileiro. No entanto, o corte no número de trabalhadores não impediu a companhia de entrar numa nova crise de insolvência em meados dos anos de 1980 (LLOYD BRASILEIRO, 1970-1980). 
Dentro das novas estratégias da SUNAMAM nos anos 1970, foram elaborados dois planos de construção naval, com o objetivo de formar uma grande Marinha Mercante nacional: I Programa da Construção Naval 1971-1975 (I PCN) e II Programa da Construção Naval 1975-1978 (II PCN). Ambos estavam em consonância com o I e II Plano Nacional de Desenvolvimento (PND), numa época em que a economia brasileira crescia em média $8,5 \%$ ao ano. No I PCN, o Lloyd Brasileiro foi responsável pela encomenda de 14 embarcações, sendo 10 cargueiros, dois frigoríficos e dois graneleiros; no II PCN, foram mais 13 grandes encomendas, 10 cargueiros, dois tipos especiais e um roll-on-roll-off, além de 40 barcaças.

O ciclo virtuoso do Lloyd Brasileiro, após a reestruturação em 1967, permitiu acumular quinze anos de superávit financeiro, inclusive gerando dividendos para a União. Pela primeira vez, a companhia entrou numa fase de prosperidade fora de um período atípico, como foi durante a Primeira e a Segunda Guerras Mundiais. Em 1974, o volume de carga transportada, pela primeira vez, superou o recorde anterior de 1941, chegando a 2.691 .100 toneladas.

$\mathrm{Na}$ segunda metade dos anos de 1970, o país internalizou, por completo, os adventos da Segunda Revolução Industrial, da grande indústria eletro/metal-mecânica, pautado nas metas expressas no II PND, que, apesar das limitações financeiras, cumpriu sua função de ampliar e integrar o parque industrial brasileiro (BELLUZZO, COUTINHO, 1984).

O final da década de 1970 mostrava sinais claros de reversão da tendência histórica de expectativas favoráveis, com crescimento acelerado ancorado no capital estatal, nacional e externo. A crise fiscal e financeira engessou o Estado, reduzindo sua mobilidade em formular novas políticas de crescimento. A quebra do padrão de financiamento, pautado na facilidade de acesso aos recursos externos e no dinheiro público, esgotou-se com a crise da economia mundial, que rebateu internamente. Os canais de financiamento interno exauriram e o sistema bancário privado doméstico era incapaz de assumir o risco dos empréstimos de longo prazo (BAER, 1993).

Paralelo à desaceleração da economia brasileira, assistimos também ao ressurgimento das dificuldades financeiras e produtivas do Lloyd Brasileiro. Mesmo gerando resultados financeiros positivos, os relatórios anuais da companhia apontavam problemas como a queda nos volume 
de carga transportada, que passou do pico de 2.691.100 toneladas, em 1974, frequentando 250 portos em todos os continentes, para 1.859.800, em 1978, ou seja, um decréscimo de 30,89\% em apenas quatro anos (LLOYD BRASILEIRO, 1974-1980). Na verdade, esta situação não se reverteu mais, pelo contrário, foi-se agravando a cada ano (Anexo 1). Se, por um lado, houve uma renovação da frota com as novas encomendas estabelecidas nos planos globais da empresa, por outro, os vencimentos dos empréstimos ocorreram justamente num período de crise econômica para o Lloyd Brasileiro e para a economia brasileira.

Em 1982, após 18 anos de sucessivos superávits, a companhia voltou a gerar resultados financeiros negativos. Os motivos apontados pela empresa foram os seguintes:

As graves dificuldades econômicas de 1982, no plano internacional, e na própria economia brasileira, afetaram a atividade de transporte marítimo de longo curso, na carga geral e no granel, refletindo no resultado econômico do Lloyd Brasileiro em 1982. As toneladas transportadas na carga geral caíram $8,8 \%$ na exportação e $34,4 \%$ na importação, representando uma queda global de 20,3\%; no transporte de granéis, a retração foi de 10,1\% na exportação e de $13,0 \%$ na importação. Tal desempenho, aliado às condições desfavoráveis do mercado de fretes de granéis, fez com que, no total, a receita operacional registrasse comportamento bastante inferior ao esperado. Em função disso o resultado final do exercício de 1982, pela primeira vez em quase duas décadas, registrou um prejuízo de Cr\$3.404 milhões. (LLOYD BRASILEIRO, 1983:3).

O volume de carga transportada seguiu a trajetória de queda, chegando a 1.342.800 toneladas em 1983, voltando aos patamares dos meados dos anos de 1960. A frota estava renovada, havia afretamentos, as exportações brasileiras avançavam, o quadro de funcionários estava enxuto, mas o Lloyd Brasileiro voltava aos seus velhos tempos de insolvência. As metas globais para novas aquisições, previstas nos planos da empresa, foram todas canceladas, os afretamentos também foram suspensos, sendo substituídos pelos navios que estavam parados (LLOYD BRASILEIRO, 1980-1984). E, para piorar a situação, foram eliminadas algumas linhas, e outras passaram a ser atendidas por navios que faziam o mesmo percurso (LLOYD BRASILEIRO, 1985). 
A crise no Lloyd Brasileiro também era um reflexo da que estava instalada na SUNAMAN. No final do governo Figueiredo, foram descobertas várias irregularidades nos repasses de recursos da SUNAMAM para os construtores navais. Mesmo assim, mergulhada em dívidas, a autarquia avalizava os estaleiros para descontar duplicatas na rede bancária e continuar a construir os navios encomendados. Em 1984, o governo não reconheceu o aval da SUNAMAM e deu início a uma apuração das irregularidades, o que ficou conhecido como o "Escândalo da SUNAMAM". Na época, estima-se que as perdas para os cofres públicos foram de 545 milhões de dólares (SENADO FEDERAL, 1986).

A segunda metade dos anos de 1980 foi de profunda agonia para a empresa, que estava prestes a completar 100 anos, e havia transportado mais de 111 milhões de toneladas, numa trajetória de fortalecimento do mercado interno. Além disso, o Lloyd Brasileiro era o instrumento da política da Marinha Mercante brasileira, que participava ativamente nas Conferências de Fretes e que garantiu ao Brasil o critério 40-40-20 (40\% do transporte de cargas por navios de bandeira brasileira, $40 \%$ por navios de bandeira do parceiro comercial do Brasil e $20 \%$ por navios da chamada $3^{\mathrm{a}}$ bandeira).

Mesmo se adaptando às novas tecnologias do setor da navegação, como a compra e afretamento de navios full contêineres, o volume da carga caía sucessivamente, registrando, em 1989, o total de 1.248.800 toneladas, o valor médio dos anos de 1920. Com o aumento da capacidade ociosa, foram desativados 20 navios e devolvidos 3 estrangeiros. Em compensação, as dívidas cresciam de forma exponencial (LLOYD BRASILEIRO, 1990; LLOYD BRASILEIRO, 1991).

Diante de um novo quadro de insolvência, que, segundo os relatórios da companhia, se devia à crise mundial no setor da navegação, a diretoria encaminhou cinco pedidos de aportes financeiros ao sócio majoritário, ou seja, à União, para saldar dívidas em atraso com o BNDES e o Banco do Brasil. Num amplo diagnóstico realizado pela empresa em 1987, as causas imediatas da crise eram as seguintes:

A empresa apresenta atualmente dois tipos distintos de problemas: o primeiro referente à impossibilidade de pagamento dos navios, cujas origens remontam a 1982 e cuja solução independe da ação gerencial. O segundo diz respeito à área operacional, que vinha se agravando desde o final de 
1985 e em cujo equacionamento vem se concentrando a atual administração (LLOYD BRASILEIRO, 1987:2)

Havia dois tipos de dívidas que deveriam ser sanadas, as de curto prazo, no valor de US $\$ 55,1$ milhões, e as de médio prazo, de US\$266,7 milhões, devidas ao BNDES/FMM, US\$ 118,7 milhões, e, o Banco do Brasil, US\$148,0 milhões. "O não pagamento dessa dívida e os sucessivos impactos das correções cambiais correspondentes fizeram com que os prejuízos acumulados atingissem, em 1985, um valor equivalente a 109\% do capital social da empresa, tornando negativo o seu patrimônio líquido (LLOYD BRASILEIRO, 1987:10)

Esta situação de inadimplência provocou o arresto de navios da companhia em portos estrangeiros. A única solução seria novos aportes financeiros, que não eram realizados desde 1966. É bom lembrar que, nesse momento, ainda estava em evidência o "escândalo da SUNAMAM". E, para completar, estávamos entrando na era neoliberal, que abominava as estatais, portanto, não havia mais espaço para novas intervenções saneadoras do Estado, como ocorreu em 1894, 1913, 1920, 1937 e 1966.

No final de 1987, foi montado um grupo de trabalho coordenado pela SUNAMAM e pelo Ministério dos Transportes, com o objetivo de analisar a viabilidade de uma possível privatização, liquidação ou saneamento do Lloyd Brasileiro. A recomendação foi de sanear financeiramente a empresa (SUPERINTENDÊNCIA NACIONAL DA MARINHA MERCANTE, 1988).

Porém, todos os apelos foram inócuos junto ao Palácio do Planalto, que estava determinado a iniciar o processo de privatização das estatais deficitárias. A resposta veio com a publicação do Decreto n. 97.455, de 15 de janeiro de 1989, que extinguiu e dissolveu nove entidades da administração federal, entre elas a Empresa de Navegação da Amazônia, a Companhia de Navegação do São Francisco, o Serviço de Navegação da Bacia do Prata e a Companhia de Navegação Lloyd Brasileiro. Mesmo com a revogação deste decreto, nos meses seguintes, que anulou temporariamente o processo de privatização, as coordenadas para o futuro do Lloyd Brasileiro já estavam definidas. Era apenas uma questão de tempo, ou melhor, de pouco tempo. 


\section{Extinção e liquidação - 1989-2002}

Os efeitos das políticas neoliberais atingiram diretamente a Marinha Mercante e a indústria da construção naval brasileira. Se, a partir do "escândalo da SUNAMAM", o setor da navegação vinha seguindo uma trajetória de crise, a continuação da recessão e os efeitos do desmonte do Estado quase levaram à extinção a indústria da construção naval dos armadores nacionais e do Lloyd Brasileiro.

Os anos noventa inauguraram uma nova fase para a economia brasileira. Durante um longo período, que se iniciou em 1930 e se estendeu até o final dos anos setenta, o Estado brasileiro teve uma ampla margem de manobra para manipular políticas econômicas em prol da industrialização. Na década de 1980, assistimos ao avanço de alguns setores da economia, como o complexo agroindustrial, mineral e petroquímico, porém, no conjunto, o nível de crescimento do PIB industrial foi muito baixo. As tentativas malfadadas de estabilizar os preços agravaram ainda mais o quadro de instabilidade econômica, que estava sendo dominado pelas finanças especulativas.

Iniciamos a década de 1990 aprofundando o endividamento externo e a crise fiscal e financeira, acrescidos da abertura comercial e financeira. A tônica da década foi o desmonte do Estado, com privatizações, desnacionalizações, fechamento de autarquias e cortes orçamentários nos investimentos. A dinâmica especulativa, com alta mobilidade de capitais e juros estratosféricos, ditava a agenda da economia nacional. As políticas de desenvolvimento e a industrial foram suplantadas pelos objetivos da macroconjuntura econômica. A recessão, que já havia assolado a economia brasileira nos anos de 1980, seguiu sua trajetória, acrescida do aumento exponencial do desemprego (CARNEIRO, 2002). Sem financiamento e novos investimentos, a infra-estrutura logística do país foi sendo rapidamente sucateada.

Após publicação do decreto que previa a extinção ou a dissolução do Lloyd Brasileiro, rapidamente a diretoria fez uma ampla reestruturação, que contou com o apoio de todos os funcionários, sem aporte do Tesouro. $\mathrm{Na}$ área comercial, foram finalmente extintas linhas deficitárias, desativados os navios obsoletos, realizado o joint-service, diminuída a rotação das viagens, além de outras medidas de cunho administrativo. Como resultado, após um esforço hercúleo, a companhia fechou o ano 
com saldo positivo de NCz $\$ 160,9$ milhões. Também foram desmobilizados ativos com a venda de oito embarcações, totalizando 103.238 TPB (LLOYD BRASILEIRO, 1990).

O Decreto n. 97.611, de 4 de abril de 1989, revogou o Decreto n.97.455, de 15 de janeiro de 1989, porém a extinção ou a privatização era uma questão de tempo, ou melhor, de pouco

tempo. Mesmo assim, as consequências do primeiro decreto foram nefastas para a empresa, que denegriram a sua imagem, levando-a a perdas irrecuperáveis de clientes, cujo prejuízo chegou a quase 40 milhões de dólares. E para completar, o Plano Collor, de março de 1990, confiscou os recursos que a empresa tinha nos bancos para saldar débitos de curtíssimo prazo (LLOYD BRASILEIRO, 1990).

A inadimplência com fornecedores, armadores e locadores de contêineres levou o arresto de 10 embarcações no exterior, em setembro de 1990. Somente por meio da intervenção da União, os navios foram liberados, sem contar as ajudas do Fundo Naval e do Ministério da Marinha, que amenizaram as dívidas dos navios arrestados no exterior. Este conjunto de turbulências, inevitavelmente, conduziu o Lloyd Brasileiro ao Plano Nacional de Desestatização, por meio do Decreto n. 427, de 16 de janeiro de 1992 (LLOYD BRASILEIRO 1993). "No final do primeiro trimestre do ano de 1993, a empresa estava fora de todos os tráfegos de carga geral e apenas atuava no segmento de granéis, embora praticamente restrita a América do Sul para evitar arrestos" (LLOYD BRASILEIRO, 1993:3).

Como medida paliativa para manter em funcionamento a estrutura administrativa e as atividades comerciais ainda restantes, o executivo federal editou várias medidas provisórias, entre 1994 e 1997, autorizando a liberação de crédito junto ao FMM, vinculado ao BNDES.

No ano seguinte, em 1994, seguiram os arrestos de navios, e a empresa foi a leilão por três vezes, sem nenhum sucesso, com o preço mínimo de US $\$ 26,6$ milhões. Este preço era contestado pelos sindicatos dos trabalhadores ligados à empresa, que alegavam que o seu patrimônio chegava a US\$ 200 milhões. Para tentar vendê-lo, o Tesouro assumiu uma dívida de US\$ 167 milhões junto ao FMM, e deu aval na negociação com o banco alemão KFW, um total de US\$ 32 milhões. As empresas interessadas teriam um empréstimo garantido de US $\$ 15$ milhões, junto ao Banco do Brasil, para viabilizar a compra. Em compensação, o novo 
proprietário teria que arcar com US\$130 milhões das dívidas, sendo a metade, trabalhistas (LLOYD BRASILEIRO, 1995).

O Decreto n. 1.746, de 14 de dezembro de 1995, dissolveu e extinguiu em definitivo a companhia, que entrou em processo de liquidação. A partir deste momento, com base em outros decretos, a comissão encarregada da liquidação foi realizando a venda dos ativos imobilizados e dos navios, além de fazer os acertos das demissões voluntárias e de passivos trabalhistas (MINISTÉRIO DO PLANEJAMENTO, ORÇAMENTO E GESTÃO, 2002).

Por fim, o Decreto de 11 de dezembro de 2002 encerrou os trabalhos de extinção da ex-centenária Companhia de Navegação Lloyd Brasileiro.

\section{Considerações finais}

A trajetória da Companhia de Navegação Lloyd Brasileiro é a trajetória da dinâmica da economia brasileira durante o século XX. No Lloyd Brasileiro, residem elementos da complexidade e da totalidade das ações do Estado na formação de um sistema nacional de economia. A longa trajetória de déficit financeiro, combinada com curtos períodos de resultados positivos, pode ser explicada pelas seguintes ações e estratégias da empresa:

a) manutenção de linhas deficitárias, com objetivos de atender a regiões mais isoladas, ou que não eram atendidas por outras empresas;

b) aquisição de empresas insolventes e de embarcações obsoletas;

c) alto custo de manutenção das embarcações obsoletas;

d) baixo valor das passagens e dos fretes para carga;

e) excesso de funcionários.

Os períodos de maior estabilidade financeira foram em três momentos de exceção da história mundial e nacional: Primeira Guerra Mundial, Segunda Guerra Mundial e a ditadura militar. Os momentos de inflexão no regime administrativo e patrimonial foram, justamente, para saldar os excessos de débitos, que conduziam a empresa para a insolvência, como foi em 1894, 1913, 1920, 1937, 1966 e após 1992. Porém, o que diferencia a última assistência financeira em relação às demais é que, nas 
primeiras, o objetivo era recuperar a empresa para fortalecê-la, já no último, era para privatizá-la. Nos anos de 1990, o movimento já era outro, ou seja, do desmonte do Estado, ao contrário do período anterior, que tinha o Estado como um agente fundamente para o desenvolvimento econômico.

Mesmo com toda a turbulência financeira e administrativa, o Lloyd Brasileiro seguiu durante toda a sua existência como sinônimo da navegação brasileira:

a) integrava comercialmente todo o território nacional;

b) frequentava em torno de 250 portos, em todos os continentes;

c) evitava o desmantelamento de empresas de navegação, via aquisições;

d) representava o Brasil nas Conferências de Fretes, em que eram definidas as cotas de cada país na navegação de longo curso;

e) junto com a FRONAPE e a DOCENAVE, era o principal instrumento da política nacional da Marinha Mercante na elaboração e na execução dos PCNs;

f) era um instrumento na captação de recursos externos.

A trajetória do Lloyd Brasileiro foi de déficit financeiro e desenvolvimento econômico. O déficit era apropriado pela economia nacional, que se estava fortalecendo, integrando o mercado e formando um sistema nacional de economia. $\mathrm{Na}$ verdade, está também foi a trajetória do sistema ferroviário brasileiro. A opção pelas rodovias também deve ser entendida como uma estratégia de transferir para o setor privado os ônus da função de transportar mercadorias e pessoas por todo território nacional.

\section{Fontes}

\subsection{Decretos, decretos-leis e leis}

BRASIL, Decreto n. 10.106, de 10 de novembro de 1888. Brasília: Senado Federal. Disponível em <http://www6.senado.gov.br/sicon> Acesso entre maio e agosto de 2008.

, Decreto n. 208, de 19 de fevereiro de 1890. Brasília: Senado Federal. Disponível em <http://www6.senado.gov.br/sicon> Acesso entre maio e agosto de 2008 . 
BRASIL, Decreto n. 857, de 13 de outubro de 1890. Brasília: Senado Federal. Disponível em <http://www6.senado.gov.br/sicon> Acesso entre maio e agosto de 2008.

, Decreto n. 611, de 22 de outubro de 1891. Brasília: Senado Federal. Disponível em <http://www6.senado.gov.br/sicon> Aceso entre maio e agosto de 2008.

Decreto n. 10.387, de 13 de agosto de 1913. Brasília: Senado Federal. Disponível em <http://www6.senado.gov.br/sicon> Acesso entre maio e agosto de 2008.

, Decreto n. 14.577, de 28 de dezembro de 1920. Brasília: Senado Federal. Disponível em <http://www6.senado.gov.br/sicon> Acesso entre maio e agosto de 2008.

, Decreto n. 20.547, de 21 de outubro de 1931. Brasília: Senado Federal. Disponível em <http://www6.senado.gov.br/sicon> Acesso entre maio e agosto de 2008.

, Decreto n. 24.147, de 20 de abril de 1934. Brasília: Senado Federal. Disponível em <http://www6.senado.gov.br/sicon $>$ Acesso entre maio e agosto de 2008.

, Decreto n. 1.708, de 11 de junho de 1937. Brasília: Senado Federal. Disponível em <http://www6.senado.gov.br/sicon> Acesso entre maio e agosto de 2008.

, Decreto n. 97.455, de 15 de janeiro de 1989. Brasília: Senado Federal. Disponível em <http://www6.senado.gov.br/sicon> Acesso entre maio e agosto de 2008.

Decreto n. 97.611, de 04 de abril de 1989. Brasília: Senado Federal. Disponível em <http://www6.senado.gov.br/sicon> Acesso entre maio e agosto de 2008.

, Decreto-Lei n. 4.648, de 2 de setembro de 1942. Brasília: Senado Federal. Disponível em <http://www6.senado.gov.br/sicon> Acesso entre maio e agosto de 2008.

, Decreto-Lei n. 67, de 21 de novembro de 1966. Brasília: Senado Federal. Disponível em <http://www6.senado.gov.br/sicon> Acesso entre maio e agosto de 2008.

, Decreto n. 427, de 16 de janeiro de 1992. Brasília: Senado Federal. Disponível em <http://www6.senado.gov.br/sicon> Acesso entre maio e agosto de 2008.

, Decreto n. 1.746, de 14 de dezembro de 1995. Brasília: Senado Federal. Disponível em <http://www6.senado.gov.br/sicon> Acesso entre maio e agosto de 2008.

, Decreto de 11 de dezembro de 2002. Brasília: Senado Federal. Disponível em <http://www6.senado.gov.br/sicon> Acesso entre maio e agosto de 2008. 
BRASIL, Lei n. 3.397, de 24 de novembro de 1888. Brasília: Senado Federal. Disponível em <http://www6.senado.gov.br/sicon> Acesso entre maio e agosto de 2008.

, Lei n. 420, de 10 de abril de 1937. Brasília: Senado Federal. Disponível em < http://www6.senado.gov.br/sicon> Acesso entre maio e agosto de 2008.

\subsection{Relatórios, anuários e projetos}

BRASIL. Balanço das receitas e despesas da República. Rio de Janeiro: Imprensa Nacional, 1890-1914. (série completa). Disponível em <http://memoria. nemesis.org.br> Acesso entre maio de julho de 2008.

,Relatório apresentado ao Vice-Presidente da República pelo Ministro da Indústria, Viação e Obras Públicas Antão Gomes de Farias em maio de 1892. Rio de Janeiro: Imprensa Nacional, 1892. Disponível em <http:// www.crl.edu/pt-br/brazil>. Acesso em maio de 2009.

,Relatório apresentado ao Vice-Presidente da República pelo Ministro da Indústria, Viação e Obras Públicas Severino dos Santos Vieira no ano de 1899. Rio de Janeiro: Imprensa Nacional, 1894. Disponível em <http:// www.crl.edu/pt-br/brazil>. Acesso em maio de 2009.

Relatório apresentado ao Presidente da República pelo Ministro da Viação e Obras Públicas Francisco de Sá. Rio de Janeiro: Imprensa Nacional, 1910. Disponível em <http://www.crl.edu/pt-br/brazil > Acesso em maio de 2009.

,Relatório apresentado ao Presidente da República pelo Ministro da Viação e Obras Públicas José Barbosa Gonçalves. Rio de Janeiro: Imprensa Nacional, 1912. Disponível em <http://www.crl.edu/pt-br/brazil >. Acesso em maio de 2009.

,Relatório apresentado ao Presidente da República pelo Ministro da Fazenda João Pandiá Calógeras. Rio de Janeiro: Imprensa Nacional, 1915. Disponível em <http://www.crl.edu/pt-br/brazil > Acesso em maio de 2009.

, Relatório apresentado ao Presidente da República pelo Ministro da Viação e Obras Públicas Augusto Tavares de Lyra. Rio de Janeiro: Imprensa Nacional, 1917. Disponível em <http://www.crl.edu/pt-br/brazil >.Acesso em maio de 2009.

Relatório apresentado ao Presidente da República pelo Ministro da Viação e Obras Públicas Augusto Tavares de Lyra no ano de 1917. Rio de Janeiro: Imprensa Nacional, 1918. Disponível em <http://www.crl.edu/pt-br/ brazil>. Acesso em maio de 2009.

Relatório apresentado ao Presidente da República pelo Ministro da Viação e Obras Públicas J. Pires do Rio. Rio de Janeiro: Imprensa Nacional, 1922. Disponível em <http://www.crl.edu/pt-br/brazil >.Acesso em maio de 2009. 
BRASIL, Mensagem enviada ao Congresso Nacional pelo Presidente da República Getúlio Vargas. Rio de Janeiro: Imprensa Nacional, 1952. Disponível em $<$ http://www.crl.edu/pt-br/brazil>. Acesso em maio de 2009.

, Mensagem enviada ao Congresso Nacional pelo Presidente da República João Goulart. Rio de Janeiro: Imprensa Nacional, 1964. Disponível em $<$ http://www.crl.edu/pt-br/brazil>. Acesso em maio de 2009.

II Plano Nacional de Desenvolvimento Econômico 1975-1979. Brasília: Presidência da República, 1974.

COMISSÃO DA MARINHA MERCANTE. Relatórios das atividades da Comissão da Marinha Mercante. Rio de Janeiro, 1956-1966. (série incompleta)

CONSELHO DO DESENVOLVIMENTO. Reaparelhamento da marinha mercante. Rio de janeiro: Presidência da República, doc. n. 2, 1956.

LLOYD BRASILEIRO. Relatório apresentado ao Ministro da Fazenda João Pandiá Calegeras relativo ao ano de 1916. Rio de Janeiro:Tipografia Martins Araújo, 1917.

Relatório apresentado ao Ministro da Viação e Obras Públicas José Pires do Rio. Rio de Janeiro: Imprensa Nacional, 1919.

Relatório do exercício de 1923. Rio de Janeiro: Imprensa Nacional, 1924.

, Relatório apresentado ao Ministro da Fazenda Annibal Freire da Fonseca pela Comissão de Liquidante referente ao período de 8 de novembro de 1921 a 31 de outubro de 1926. Rio de Janeiro: Imprensa nacional, 1929.

, Relatórios apresentados ao Ministro da Viação e Obras Públicas. Rio de Janeiro 1942-1966. (série completa)

Anuários do Lloyd Brasileiro. Rio de Janeiro, 1970-1985. (série completa).

, Plano global da empresa. Rio de Janeiro, 1971-1985. (série completa)

Lloyd Brasileiro: desempenho no período 1982/1984 e perspectivas. Rio de Janeiro, 1985.

, Antecedentes da crise econômico-financeira e soluções propostas. Rio de Janeiro, 1987.

Evolução recente. Rio de Janeiro, 1990.

, O Lloyd Brasileiro: apresentação, lista de transparência, anexos. Rio de Janeiro, 1990.

A crise econômico-financeira do Lloyd Brasileiro: antecedentes e resumo histórico. Rio de Janeiro, 1991.

, Parecer dos auditores independentes. Rio de Janeiro, 1993.

, Relatório da Auditória 001/95. Rio de Janeiro, 1995.

MINISTÉRIO DA FAZENDA. Controladoria Central da República: balanço geral da União. Rio de Janeiro: Imprensa Nacional, 1923-1963. (série completa) 
MINISTÉRIO DO PLANEJAMENTO, ORÇAMENTO E GESTÃO. Acervo da extinta Companhia de Navegação Lloyd Brasileiro - Lloydbras. Brasília: Secretaria Executiva, 2002.

SUPERINTENDÊNCIA NACIONAL DA MARINHA MERCANTE. Anuário da marinha mercante. Rio de Janeiro, 1968-1985. (série completa)

, Relatório do Grupo de Trabalho que estudou as propostas de privatização da Companhia de Navegação Lloyd Brasileiro. Rio de Janeiro, 1988.

SENADO FEDERAL. CPI SUNAMAM: relatório final da comissão. Brasília: Imprensa Oficial, 1986.

\subsection{Referências bibliográficas}

AURELIANO, Liana Maria, No limiar da industrialização. São Paulo: Brasiliense, 1981.

BAER, Mônica, O rumo perdido: a crise fiscal e financeira do Estado brasileiro. São Paulo: Paz e Terra, 1993.

BELlUZZO, Luiz Gonzaga de Mello, COUTINHO, Luciano, "Política econômica, inflexão e crise",1974-1981. In: BELLUZZO, Luiz Gonzaga de Mello e COUTINHO, Renata, Desenvolvimento capitalista no Brasil: ensaios sobre a crise. Brasiliense: São Paulo, 1984.

BURLAMAQUI, Armando, A marinha mercante brasileira 1822-1914. Rio de Janeiro: Imprensa Nacional, 1918.

CARNEIRO, Ricardo, Desenvolvimento em crise: a economia brasileira no último quarto do século XX. São Paulo: Editora da Unesp; Campinas: IE/UNICAMP, 2002.

FROTA, Fernando, De porque não se conserta a marinha mercante brasileira. Rio de Janeiro: Editora do Autor, 1965.

GAMA, Arthur Oscar Saldanha da, A marinha mercante do Brasil na I Guerra Mundial. Rio de Janeiro: Capemi, 1982.

GUIMARÃES, José Celso de Macedo Soares, Navegar é preciso: crônicas de muitas lutas - as lutas. vol. 1, Rio de Janeiro: Rio Fundo, 1996.

JACEGUAY, Barão de, Companhia nacional de navegação a vapor entre o Brasil e a Europa. Rio de Janeiro: Tipografia de G. Leuzinger \& Filhos, 1888.

LOBO, Ubaldo, Notícia histórica e avaliação dos bens do Lloyd Brasileiro. Rio de Janeiro: Empresa Brasil Editora, 1922.

MENDONÇA, Lauro Nogueira Furtado de, "A marinha imperial 1870 a 1889”. In: História naval brasileira. vol. IV, Rio de Janeiro: Serviço de Documentação da Marinha, 2001.

SILVA, Francisco Romano Stepple, Resumo histórico das companhias de navegação a vapor subvencionadas e privilegiadas nos Estados Unidos do Brasil de 1808 a 1900. Rio de Janeiro:Tipografia da Estatística, 1902.

SUZIGAN, Wilson, Indústria brasileira: origem e desenvolvimento. Campinas, São Paulo: Editora da UNICAMP; HUCITEC, 2000. 


\section{Anexo 1 - Evolução do desempenho produtivo e financeiro da Companhia de Navegação Lloyd Brasileiro 1890-1994}

\begin{tabular}{|c|c|c|c|c|c|c|c|}
\hline Ano & Navios & $\begin{array}{c}\mathrm{TPB} \\
\text { próprio }\end{array}$ & $\begin{array}{c}\text { Carga } \\
\text { transportada } \\
(\text { carga geral } t)\end{array}$ & $\begin{array}{c}\text { Participação } \\
\text { na frota } \\
\text { nacional } \\
\text { TPB (em \%) } \\
\end{array}$ & $\begin{array}{c}\text { Resultado } \\
\text { financeiro } \\
\text { (valores correntes) }\end{array}$ & Trabalhadores & Subvenção \\
\hline 1890 & 27 & 27.947 & & & & & \\
\hline 1892 & 64 & 47.230 & 128.688 & & & & $1.487: 454 \$ 600$ \\
\hline 1894 & 65 & 46.676 & 40.733 & & & & \\
\hline 1896 & 58 & 44.148 & 72.990 & & & & $1.340: 636 \$ 960$ \\
\hline 1898 & 49 & 39.537 & 60.587 & & & & $1.312: 430 \$ 072$ \\
\hline 1900 & 47 & 38.158 & 69.413 & & & & $1.386: 572 \$ 365$ \\
\hline 1902 & 47 & 38.158 & 57.919 & & & & $1.221: 516 \$ 640$ \\
\hline 1904 & 30 & 31.853 & 98.598 & & $1.836: 158 \$ 310$ & & $1.194: 596 \$ 790$ \\
\hline 1906 & 45 & 62.665 & 141.703 & & & & $1.051909 \$ 350$ \\
\hline 1908 & 51 & 75.827 & 391.720 & 59,24 & & & $1.668: 697 \$ 778$ \\
\hline 1910 & 67 & 102.259 & 455.819 & 55,58 & & & $1.668: 697 \$ 778$ \\
\hline 1912 & 64 & 98.539 & 522.870 & 48,78 & & & $1.668: 697 \$ 778$ \\
\hline 1914 & 64 & 98.539 & 451.315 & 44,19 & $(9.293: 819 \$ 667)$ & & 1.663:699\$992 \\
\hline 1916 & 57 & 90.440 & 619.730 & 46,14 & $15.759: 301 \$ 662$ & & $3.663: 699 \$ 992$ \\
\hline 1918 & 100 & 313.458 & 949.631 & & $20.366: 733 \$ 532$ & & $3.663: 699 \$ 992$ \\
\hline 1920 & 98 & 309.759 & 490.230 & & $(23.326: 854 \$ 565)$ & 5.671 & $3.663: 699 \$ 992$ \\
\hline 1922 & 94 & 272.000 & 851.292 & 80,71 & $(12.037: 931 \$ 683)$ & & $6.000: 000 \$ 000$ \\
\hline 1924 & 88 & 268.000 & 1.135 .067 & 85,62 & $26.162: 113 \$ 917$ & & $6.000: 000 \$ 000$ \\
\hline 1926 & 87 & 290.000 & 1.256 .293 & 74,94 & 13.311:081\$929 & & $6.000: 000 \$ 000$ \\
\hline 1928 & 86 & 286.000 & 1.250 .000 & 69,76 & & & $18.000: 000 \$ 000$ \\
\hline 1930 & 82 & 283.000 & 1.230 .000 & 70,75 & $(17.514: 000 \$ 000)$ & & $18.000: 000 \$ 000$ \\
\hline 1932 & 81 & 277.000 & 1.200 .000 & 81,23 & $7.290: 000 \$ 000$ & & $18.000: 000 \$ 000$ \\
\hline 1934 & 78 & 260.000 & 1.187 .000 & 72,83 & & & $20.000: 000 \$ 000$ \\
\hline 1936 & 62 & 230.000 & 1.010 .000 & 65,71 & & & $20.000: 000 \$ 000$ \\
\hline 1938 & 68 & 248.000 & 1.090 .000 & & $(4.500 .000)$ & & $40.000: 000 \$ 000$ \\
\hline 1940 & 81 & 218.000 & 1.380 .000 & & 14.500 .000 & & $40.000: 000 \$ 000$ \\
\hline 1942 & 93 & 358.000 & 1.790 .000 & 60,78 & $(14.673 .973)$ & & $40.000 .000,00$ \\
\hline 1944 & 68 & 290.000 & 2.100 .000 & 56,20 & 44.078 .628 & & $40.000 .000,00$ \\
\hline 1946 & 66 & 270.000 & 1.620 .000 & 50,75 & 20.805 .247 & & $40.000 .000,00$ \\
\hline 1948 & 90 & 395.000 & 2.130 .000 & 52,39 & 4.296 .781 & 12.600 & $40.000 .000,00$ \\
\hline 1950 & 86 & 373.000 & 2.127 .398 & 65,55 & $(101.468 .549)$ & 12.780 & $40.000 .000,00$ \\
\hline 1952 & 83 & 350.000 & 1.904 .088 & & $(66.835 .729)$ & 11.000 & $40.000 .000,00$ \\
\hline 1954 & 81 & 313.000 & 1.924 .640 & 35,81 & $(142.580 .834)$ & 9.528 & $40.000 .000,00$ \\
\hline 1956 & 64 & 278.000 & 1.900 .000 & 31,63 & 470.000 .000 & 9.100 & \\
\hline 1958 & 64 & 278.000 & 1.663 .000 & 27,10 & 312.251 .083 & 8.235 & \\
\hline 1960 & 72 & 326.000 & 1.650 .000 & 25,08 & $(99.959 .199)$ & 8.000 & \\
\hline
\end{tabular}




\begin{tabular}{l|c|c|c|c|c|c|c}
\hline Ano & Navios & $\begin{array}{c}\text { TPB } \\
\text { próprio }\end{array}$ & $\begin{array}{c}\text { Carga } \\
\text { transportada } \\
\text { (carga geral t) }\end{array}$ & $\begin{array}{c}\text { Participação } \\
\text { na frota } \\
\text { nacional } \\
\text { TPB (em \%) }\end{array}$ & $\begin{array}{c}\text { Resultado } \\
\text { financeiro } \\
\text { (valores correntes) }\end{array}$ & Trabalhadores & Subvenção \\
\hline 1962 & 53 & 236.000 & 1.125 .000 & 17,42 & 1.414 .181 .324 & 8.097 & \\
\hline 1964 & 55 & 264.000 & 1.077 .744 & 18,54 & 3.706 .529 .785 & 8.042 & \\
\hline 1966 & 77 & 490.000 & 1.216 .930 & 34,46 & 8.511 .091 .820 & 6.447 & \\
\hline 1968 & 50 & 478.773 & 1.640 .000 & 27,98 & 5.146 .037 & 6.022 & \\
\hline 1970 & 31 & 280.963 & 1.868 .100 & 12,01 & 12.933 .596 & 2.800 & \\
\hline 1972 & 39 & 290.846 & 1.860 .300 & 11,36 & 36.697 .775 & 2.605 & \\
\hline 1974 & 43 & 425.461 & 2.691 .100 & 10,35 & 186.859 .255 & 2.815 & \\
\hline 1976 & 48 & 468.277 & 2.314 .100 & 9,19 & 189.630 .000 & 2.971 & \\
\hline 1978 & 50 & 569.400 & 1.859 .800 & 9,22 & 168.111 .005 & 3.238 & \\
\hline 1980 & 43 & 554.734 & 1.891 .000 & 6,87 & 1.701 .625 .095 & & \\
\hline 1982 & 45 & 646.116 & 1.470 .600 & 6,89 & $(3.404 .470 .459)$ & & \\
\hline 1984 & 38 & 472.727 & 1.612 .600 & 4,73 & 35.301 .904 .826 & & \\
\hline 1986 & & & & & $(270.685)$ & & \\
\hline 1988 & 31 & 656.248 & 1.710 .600 & & $(99.836 .964)$ & & \\
\hline 1990 & 22 & & 212.700 & & $(1.128 .631 .900)$ & & \\
\hline 1992 & 16 & 444.085 & 291.700 & & & & \\
\hline 1994 & 10 & 349.168 & 80.600 & & & & \\
\hline Fonte: & & & & & & \\
\hline
\end{tabular}

Fonte: Relatórios do Lloyd Brasileiro; Relatórios do Ministério da Agricultura, Viação e Obras Públicas; Relatórios do Ministério da Fazenda - Balanço das receitas e despesas da República; Relatório da Comissão da Marinha Mercante; Anários da Marinha Mercante.

\section{Anexo 2: Nota metodológica}

A construção da série histórica da evolução da Companhia de Navegação Lloyd Brasileiro foi realizada com base nas seguintes fontes:

Navios, TPB e carga transportada: Relatórios do Lloyd Brasileiro de 1917, 1919, 1924, 1929, 1942-1966, 1970-1985, 1990 e 1995.

A participação do Lloyd Brasileiro na frota nacional obtivemos dividindo o Lloyd Brasileiro, disponíveis nos relatórios da companhia, pela nacional, disponíveis nos Relatórios da Comissão da Marinha Mercante 1956-1966, Anuários da Marinha Mercante 1968-1985 e Anuários Estatístico do Brasil 1937-1996 (não citado). Sendo que os dados da frota nacional não foram mostrados na tabela.

Resultado financeiro e subvenção: Relatórios do Ministério da Agricultura, Viação e Obras Públicas, Relatórios do Lloyd Brasileiro, Comissão da Marinha Mercante e Balanços das Receitas e Despesas da União 1914-1955.

Trabalhadores: Relatórios do Lloyd Brasileiro. 
As fontes primárias e as obras raras foram pesquisadas nos seguintes arquivos e bibliotecas:

Rio de Janeiro: Arquivo Nacional (Fundo da Companhia de Navegação Lloyd Brasileiro), Biblioteca Nacional, Biblioteca da Marinha, Biblioteca do Ministério da Fazenda, Biblioteca da Escola de Guerra Naval, Instituto Histórico Geográfico Brasileiro, Biblioteca do Clube Naval e Biblioteca do Clube de Engenharia

Brasília: Biblioteca do Senado Federal, Biblioteca da Câmara dos Deputados e Biblioteca do Ministério dos Transportes (Coleção Memória dos Transportes). 